\title{
An Assessment of Energetic and Exergetic Performance Analysis of Central Heating Plant in a University Campus
}

\author{
Muharrem Imal \\ Mechanical Engineering Department, Kahramanmaras S.I. University \\ 46100, Kahramanmaras, Turkey \\ E-mail: muharremimal@ksu.edu.tr,muharremimal@gmail.com
}

\begin{abstract}
Central heating and cooling plants are used in all living areas. Therefore, efficient use of energy is important. Energy and exergy analysis of the central heating plant located on the university campus was performed and the performance was evaluated. Energy and exergy analysis of the hot steam boiler and other sub-systems connected to the heating plant was performed and the results were calculated. By calculating the irreversibility, it was found that the most important exergy loss was $6067.73 \mathrm{~kW}$ in the boiler unit.
\end{abstract}

Keywords: Energy analysis, exergy analysis, steam boiler

DOI: $10.7176 / J S T R / 7-09-03$

\section{Bir Üniversite Yerleşkesindeki Merkezi Isı Santralinin Enerjetik ve Ekserjetik Performansının Değerlendirilmesi}

\begin{abstract}
Özet
Tüm yaşam alanlarında merkezi ısıtma ve soğutma santralleri kullanılmaktadır. Bu nedenle enerjinin verimli kullanılması önemlidir. Üniversite kampüsünde bulunan merkezi 1sıtma santralinin enerji ve ekserji analizi yapılarak performansı değerlendirilmiştir. Kızgın buhar kazanı ve ısı tesisine bağlı diğer sistemlerin enerji ve ekserji analizleri yapılmış ve sonuçları hesaplanmıştır. Tersinmezlik etkisi sonucu merkezi kazan ünitesinde en önemli ekserji kaybının 6067,73 kW olduğu tespit edilmiştir.
\end{abstract}

Anahtar Kelimeler: Enerji analizi, ekserji analizi, buhar kazanı

\section{Giriș}

Dünyada enerjiye olan ihtiyaç sürekli olarak artarken, enerjinin tasarruflu kullanımı da öne çıkmaktadır. Enerji ihtiyacını karşılamak için kullanılan fosil kaynaklı yakıtların yakın bir gelecekte tükenme olasılığı ve sanayileşmenin belirli bölgelerde yoğunlaşması çevre kirliliğini artırmaktadır. Bu durum, enerji geri kazanımına ve yenilenebilir enerji kaynaklarının yaygınlaşmasına yol açmaktadır. Enerjinin tasarruf yöntemlerinden birisi de 1 sıl sistemlerin enerji ve ekserji analizinin yapılarak performansının değerlendirilmesi ve sistemlerin verimini artırıcı iyileştirmeler yapılmasıdır.

Enerji analizi ve ekserji analizi ısıl sistem uygulamalarının performansını belirlemede en etkili yoldur. Enerji analizi, sistemin nicel enerji potansiyeliyle ilgili bilgi verirken, ekserji analizi de sistemlerin nitel performanslarını hesaplamada ve enerji kayıplarının olduğu noktaları belirlemede etkili bir yöntemdir. Ekserji analizi, sistemin kullanılabilir enerji değerini hesaplamada kullanılır. Yani bir sistemde verimin arttırılması için gerekli önlemlerin alınması ekserji analizinin uygulanmasını gerektirir.

Boylerin enerji ve ekserji analizini yapmışlardır. Bir termik santralinin performansını hesaplamak için enerji ve ekserji analizi yapmıştır. Bir kazan sisteminde hesaplanan enerji ve ekserji kayıplarını, yaptıkları enerji ve ekserji analizine göre ortaya koymuşlardır. Bir petrol rafinerisinde ekserji kayıplarını hesaplayarak sonuçları, daha etkili iyileştirmeler yapmak için kullanmıştır. Bir enerji 20 | P a g e www.iiste.org 
santraline enerji ve ekserji analizi uygulayarak, santraldeki ünitelerde ortaya çıkan ekserji kayıplarını hesaplamışlar ve veriminin arttırılması için çözüm önermişlerdir. Bir birleşik ısı güç tesisinin ekserji analizini yaparak, buhar enjektörünün ekserji verimine etkisini hesaplamışlardır. Birleşik 1sı ve güç üreten gaz türbinli kojenerasyon sistemine ekserji analizi uygulayarak performansını hesaplayan bir çalışma yayınlamışlardır. Enerji sisteminin optimum performansını hesaplamak için mühendislik ekonomisi ve ekserjinin birlikteliği ile termoekonomik analizi bir enerji tesisine uygulamıştır. Isı merkezinin bulunduğu yerleşke yaklaşık $240.000 \mathrm{~m}^{2}$ kapalı alana sahiptir. Kamu binalarının toplam 1sı ihtiyac1 27.220.000 kcal/h'tır . Isıtma sisteminde doğalgazla çalışan 4 adet ve her biri $6.800 .000 \mathrm{kcal} / \mathrm{h}$ kapasiteli kızgın su kazanı bulunmaktadır. Binaların ısıtma sistemi için 14 farklı noktada eşanjör ünitesi yer almaktadır. Şekil 1. 'de enerji ve ekserji analizinin uygulandığı merkezi 1sı santrali görülmektedir. Is1 merkezinde kazan sistemi yanında iki adet fan coil ve iki adet çiller sistemi de bulunmaktadır. Bu çalışmada, Kahramanmaraş S. İ. Üniversitesi yerleşkesinde 1S1 santralinin ısıtma ve soğutma sistemlerine enerji ve ekserji analizi uygulanarak elde edilen sonuçlara göre yapılan verim artırıcı çalışmalarının ardından bulunan sonuçlar ve etkileri değerlendirilmiştir.

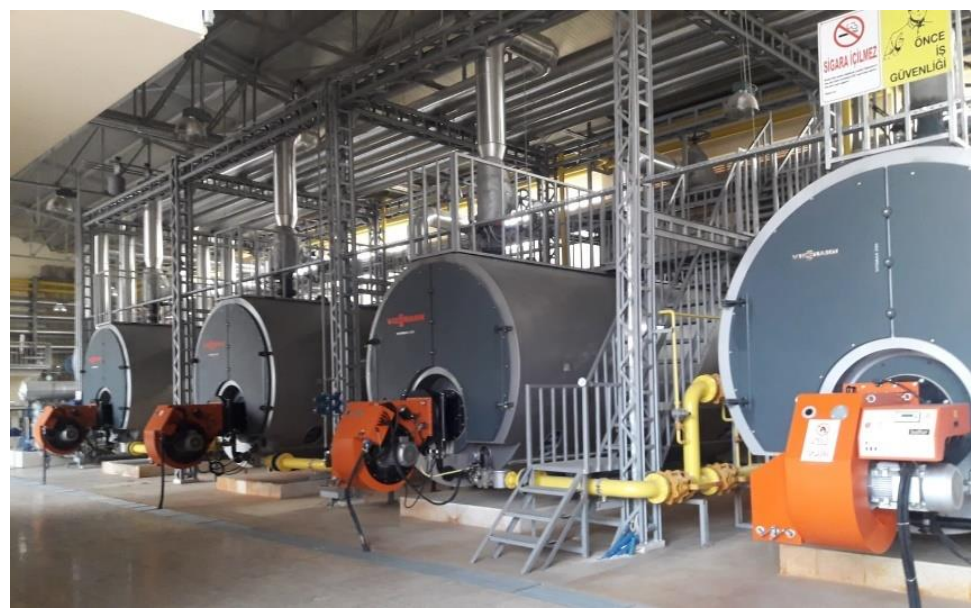

Şekil 1. Enerji ve ekserji analizinin uygulandığı merkezi kazan sistemi

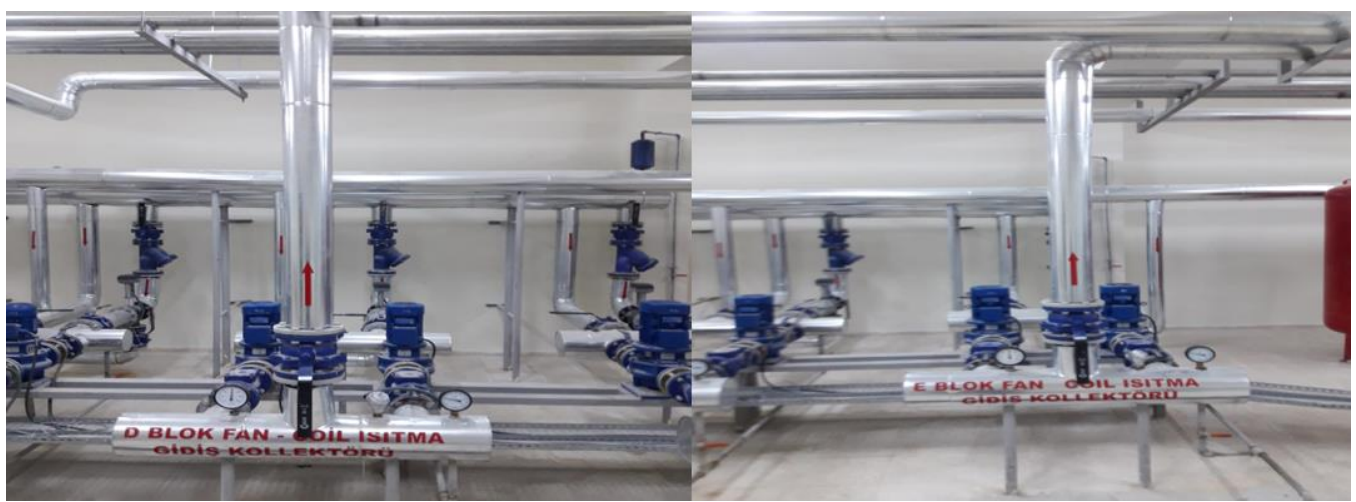

Şekil 2. Enerji ve ekserji analizinin uygulandığı 1sı santrali fan coil ve çiller dağıtım sistemi

\section{Enerji Analizi}

Enerji analizi, termodinamiğin birinci yasasına göre (Eş.1.) ve sisteme enerjinin giriş ve çıkış değerleri esas alınarak yapılır. $\mathrm{Bu}$ analiz sisteme giren enerjinin ne kadarlık bir bölümünün istenen amaçlar için kullanılabildiğini ve ne kadar enerjinin çevreye atıldığını nicel sonuçlar olarak vermektedir. $\mathrm{Bu}$ sonuçlar ile çizilen Sankey diyagramı veya Grossman diyagramı üzerinde giren ve çıkan enerji akışı gösterilir. Enerji analiz uygulamalarında enerjinin ne şekilde kullanıldı̆̆ ve hangi noktalarda verim artırıcı iyileştirmeler yapılabileceği bu diyağramlar ile belirlenir.

$$
Q-W=\Delta E
$$


Bir kontrol hacmine enerji, ısı ve iş alışverişi şeklinde giriş veya çıkış yaparken kütle giriş ve çıkışı da gerçekleşir. Kontrol hacmi içerisine kütle girişi olduğunda, sistemin toplam enerjisi artar, kontrol hacmi içerisinden bir kütle çıkışı olduğunda da, sistemin toplam enerjisi azalır. (Eş.2.)

$$
\Delta \mathrm{E}=\mathrm{Q}-\mathrm{W}+\Sigma E c ̧-\Sigma E g
$$

$Q-W$ : Sınırlardan iş ve isı olarak geçen toplam enerji.

$\Sigma \mathrm{Eg}$ : Kontrol hacmine giren kütlenin toplam enerjisi.

$\Sigma$ Eç: Kontrol hacminden çıkan kütlenin ait toplam enerjisi.

$\Delta E$ : Kontrol hacminde oluşan net enerji değişimi.

Isıtma ve soğutma sistemlerinde kontrol hacmi sınırlarından iş ve 1sı olarak geçen toplam enerji miktarı entalpi değişim miktarına eşit olur.

$$
\mathrm{Q}-\mathrm{W}=\Delta \mathrm{h}
$$

\subsection{Buhar Kazanının Enerji Analizi}

Kazanda oluşan ısı kayıplarını belirlemek için kazanın ısıl dengesinin bilinmesi gerekir. Bu değişkenler Şekil 3.'de gösterilmiştir.

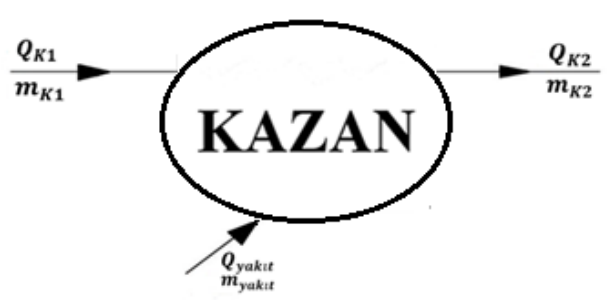

Şekil 3. Kazanın ısıl denge değişkenleri

Yakıtın yanmasıyla oluşan enerji;

$$
\dot{Q}_{y}=\dot{m}_{y} \times H_{u}
$$

eşitliğiyle hesaplanır. Burada;

$\dot{m}_{y}$ : Kullanılan yakıta ait kütlesel debi $(\mathrm{kg} / \mathrm{s})$

$H_{u}$ : Kullanılan yakıt için alt 1 sı değer $(\mathrm{kcal} / \mathrm{h})$

Kazanda oluşan enerji kaybı;

$$
\dot{Q}_{K K}=\dot{Q}_{y}-\left[\dot{m}_{K} \mathrm{x}\left(h_{K 2}-h_{K 1}\right)\right]
$$

eşitliğiyle hesaplanır. Burada;

$\dot{m}_{K}$ : Kazanda kullanılan akışkanın kütlesel debisi $(\mathrm{kg} / \mathrm{s})$

$h_{K 2}$ : Kazanın çıkış noktasında akışkanın entalpisi $(\mathrm{kJ} / \mathrm{kg})$

$h_{K 1}$ : Kazanın giriş noktasında akışkanın entalpisi $(\mathrm{kJ} / \mathrm{kg})$

\subsection{Klima Santrali Enerji Analizi}

Klima santrali içerisinde de sistem değişkenlerinin enerji dengesi yazılarak I. Kanun analizi yapılır. Klima santraline ait sistem değişkenleri Şekil 4. 'de verilmiştir. 


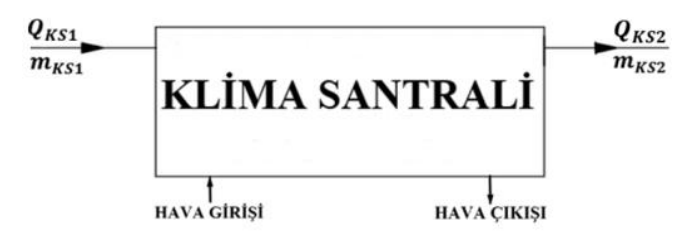

Şekil 4. Klima santrali için ısıl denge değişkenleri

Klima santrali değişkenleri belirlendikten sonra Eşitlik 2. kullanılarak enerji analizi hesabı yapılır.

$$
\dot{Q}_{K S}=\dot{m}_{K S} \times\left(h_{K S 1}-h_{K S 2}\right)
$$

Burada;

$\dot{m}_{K S}$ : Klima santralinde kullanılan akışkanın kütlesel debisi $(\mathrm{kg} / \mathrm{s})$

$h_{K S 2}$ : Klima santrali çıkışında akışkanın entalpisi $(\mathrm{kJ} / \mathrm{kg})$

$h_{K S 1}$ : Klima santrali girişinde akışkanın entalpisi $(\mathrm{kJ} / \mathrm{kg})$

\subsection{Fan Coil Hattının Enerji Analizi}

Fan coil hatıının enerji dengesi değişkenleri Şekil 5. 'de verilmiştir.

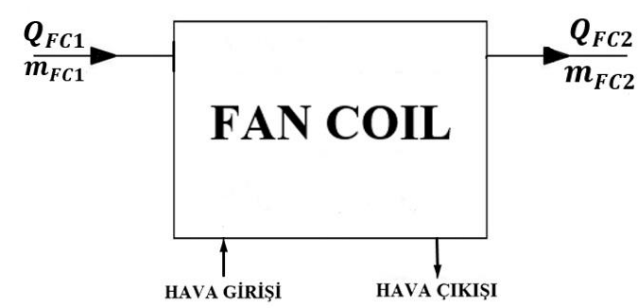

Şekil 5. Fan-coil hattı için ısıl denge değişkenleri

Fan-coil hattına ait enerji ve kütle değişkenleri belirlendikten sonra Eşitlik 7. kullanılarak enerji analizi yapilir.

$$
\dot{Q}_{F C}=\dot{m}_{F C} \mathrm{x}\left(h_{F C 1}-h_{F C 2}\right)
$$

Burada;

$\dot{m}_{F C}$ : Fan coil hattında kullanılan akışkanın kütlesel debisi $(\mathrm{kg} / \mathrm{s})$

$h_{F C 1}$ : Fan coil hattı girişinde akışkanın entalpi değeri $(\mathrm{kJ} / \mathrm{kg})$

$h_{F C 2}$ : Fan coil hattı çıkışında akışkanın entalpi değeri $(\mathrm{kJ} / \mathrm{kg})$

\subsection{Eşanjör Sisteminin Enerji Analizi}

Eşanjör sisteminin enerji analizinde enerji dengesi değişkenleri Şekil 7.'de verilmiştir.

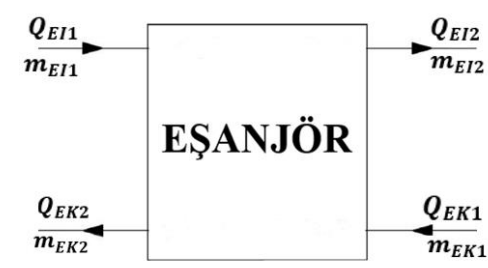

Şekil 6. Eşanjör için ısıl denge değişkenleri

Belirlediğimiz değişkenleri kullanarak eşanjörde enerji analizi aşağıdaki eşitlikle hesaplanır. 
Burada;

$$
Q_{e S}=\left[\dot{m}_{E I} \times\left(h_{E 1}-h_{E 2}\right)\right]+\left[\dot{m}_{E K S} \times\left(h_{E 3}-h_{E 4}\right)\right]
$$

$\dot{m}_{E I}$ : Eşnajör ısıtma hatıında akışkanın kütlesel debisi $(\mathrm{kg} / \mathrm{s})$

$\dot{m}_{E K S}$ : Eşanjör kullanım suyu hattındaki akışkanın kütlesel debisi (kg/s)

$h_{E 1}$ : Eşanjör ısıtma girişinde akışkanın entalpisi $(\mathrm{kJ} / \mathrm{kg})$

$h_{E 3}$ : Eşanjör kullanım suyu girişinde akışkanın entalpisi (kJ/kg)

$h_{E 2}$ : Eşanjör ısıtma çıkışında akışkanın entalpisi $(\mathrm{kJ} / \mathrm{kg})$

$h_{E 4}$ : Eşanjör kullanım suyu çıkışında akışkanın entalpisi $(\mathrm{kJ} / \mathrm{kg})$

Sistemlerin ve sistemler üzerindeki tüm elemanların enerji değerlerini hesapladıktan sonra aşağıdaki eşitlik kullanılarak ısıl verim değerleri hesaplanır.

$$
\eta_{I}=\frac{\sum \dot{Q}_{\text {Çlkan }}}{\sum \dot{Q}_{\text {Giren }}}
$$

\section{Ekserji Analizi}

Ekserji tersinir bir süreç sonucunda çevre koşulları ile sistem arasında denge sağlandığında, elde edilen kullanılabilir iş miktarını ifade etmektedir. Yani, ekserji enerjinin kullanılabilen kısmı olarak açıklanır. Ekserji iş ya da iş üretebilme yeteneğidir ve ekserjinin hesaplanmasında çevre koşullarının bilinmesi gerekmektedir.

Bir sistem hal değişimleri sonunda, çevre ile termodinamik denge durumuna geldiğinde elde edilebilecek iş miktarı o maddenin ekserjisini ifade eder. Ekserji analizi kullanılarak sistemin giren enerjiye göre nekadar verimli olduğunu anlamanın yanında, sistemin kullanılabilir işini de hesaplamamız sağlanır. Bir hal değişimi esnasında enerjinin niteliğinin azalması, entropi üretimi ve iş yapma yeteneğinin azaldığını gösterir ve sistemlerin verimini artırmak için oldukça önemli bir analizdir. Buna göre, ekserji verimi toplam çıkan ekserjinin toplam giren ekserjiye oranı olarak ifade edilebilir.

$$
\Psi=\Sigma X c ̧ / \Sigma X g
$$

Kayıp kullanılabilir ekserji, tersinmezliğe eşittir ve ekserji dengesi,

$$
\Sigma I=\Sigma X g-\Sigma X c ̧
$$

şeklinde yazilır.

\subsection{Buhar Kazanının Ekserji Analizi}

Kazanlarda, herhangi bir yakıt yakıldığında yakıtın kimyasal enerjisi 1 sı enerjisi olarak 1sıtma sisteminde kullanılan akışkana transfer edilir. Yanma olayı sonucunda açığa çıkan enerjinin tamamı akışkana aktarılamaz. Açığa çıkan ısının bir bölümü baca gazıyla, bir bölümü de kazan yüzeyinden çevreye atılmaktadır. Kazan verimi hesaplanırken atık 1sı miktarı dikkate alınması gereken önemli bir değişkendir.

Şekil 8.'de kazan hattının giriş-çıkış noktalarındaki ekserjik değişkenler gösterilmiştir. Şekildeki ekserji değişkenlerinin belirlenmesinden sonra ekserjik kayıplar hesaplanırsa, kazanın kayıp ekserjisi Eş. 14 ile hesaplanir.

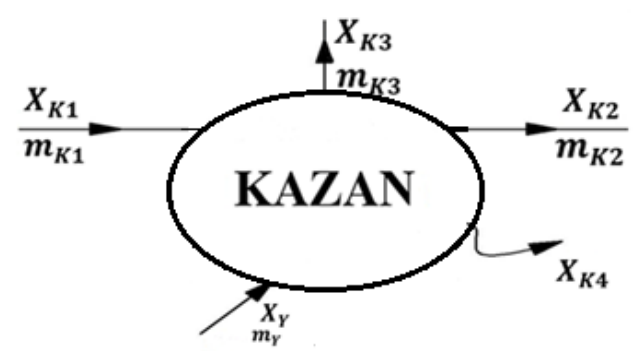

Şekil 7. Kazanın ekserjik değişkenleri

24 | P a g e

www.iiste.org 


$$
\begin{gathered}
\Sigma X_{\text {giren }}=\Sigma X_{\text {çlkan }}+\Sigma X_{\text {kayıp }} \\
X_{Y}+X_{K 1}=X_{K 2}+X_{K 4}+X_{K 3}+X_{K a y \imath p} \\
X_{\text {Kayıp }}=X_{\text {Yakıt }}+X_{K 1}-\left(X_{K 2}+X_{K 4}+X_{K 3}\right)
\end{gathered}
$$

Yakıtın yanması sonucunda oluşan ekserji hesaplanırken sistemde doğalgazın yanması sırasında yakıtın metandan $\left(\mathrm{CH}_{4}\right)$ oluştuğu kabul edilerek, yakıtın toplam ekserjisi yakıtın toplam kütlesi ile birim kütlenin ekserji değerinin çarpımı ile bulunur.

$$
\Sigma X_{K 4}=\dot{m}_{Y} x \varepsilon_{Y a k u t}
$$

Kazan yüzeylerinde gerçekleşen ekserjik kayıplar kazan yüzeyinden, kazanın bulunduğu ortama 1s1 geçişi sonucu meydana gelmektedir. Bu değer kazan yüzeyinden gerçekleşen kayıp olarak bilinir ve eşitlik 16. kullanılarak hesaplanır.

$$
\Sigma X_{K 4}=\dot{Q}_{\text {Kaylp }}\left(1-\frac{T_{0}}{T_{S}}\right)
$$

Eşitlikteki $\dot{Q}_{\text {Kayıp }}$ değeri; kazanın ekserji değerinden yakıtın yanmasıyla oluşan ekserji değerinin çıkarılmasıyla elde edilmektedir ve eşitlik 17 . ile bulunur

$Q_{\text {Kaylp }}=\dot{m}_{Y} x H_{u}-\left[Q_{\text {Kazan }}+\left(\dot{m}_{N_{2}} \Delta h_{N_{2}}+\dot{m}_{C_{2}} \Delta h_{C_{2}}+\dot{m}_{H_{2} O} \Delta h_{H_{2} O}\right)\right]$

Yukarıdaki eşitlikte hesaplanan $Q_{\text {Kayıp }}$ değeri Eşitlik 17' de kullanıldığında kazan yüzeyinden oluşan ekserjik kayıp hesaplanır.

Baca gazları için ekserji analizi hesaplanırken aşağıdaki eşitlik kullanılır.

$$
\Sigma X_{K 3}=\Sigma \dot{M}_{i} \times X_{i}
$$

Kazan girişinde ekserjik kayıp sistemde dolaşıp kazana geri dönen dönüş suyu için aşağıdaki eşitlik yardımıla hesaplanır.

$$
X_{K 1}=\dot{m}_{\text {Kazan }}\left[\left(h_{K 1}-h_{0}\right)-T_{0}\left(s_{K 1}-s_{0}\right)\right]
$$

Kazan çıkışında ekserjik kayıp kazandan çıkıp sisteme gönderilen kazan çıkış suyu için hesabı aşağıdaki eşitlik yardımıyla hesaplanır.

$$
X_{K 2}=\dot{m}_{\text {Kazan }}\left[\left(h_{K 2}-h_{0}\right)-T_{0}\left(s_{K 2}-s_{0}\right)\right]
$$

\subsection{Klima Santrali Ekserji Analizi}

Klima santral hattında oluşan ekserjik değişkenler Şekil 9. da gösterilmiştir.

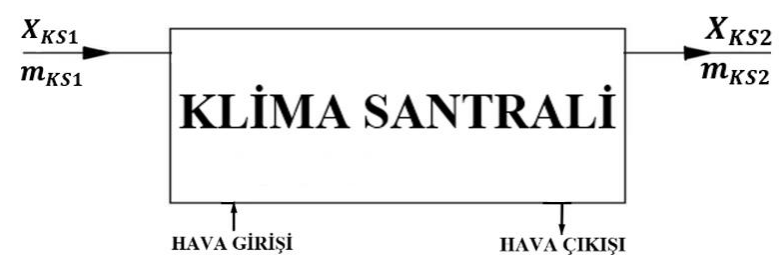

Şekil 8. Klima santrali için ekserjik değişsenler

Klima santral hattının ekserjik değeri, suyun termodinamik özellikleri yardımıla klima santrali girişi için Eşitlik 21. ile hesaplanır.

$$
X_{K S 1}=\dot{m}_{K S}\left[\left(h_{K S 1}-h_{0}\right)-T_{0}\left(s_{K S 1}-s_{0}\right)\right]
$$

25 | P a g e

www.iiste.org 
Klima santrali çıkışındaki su sıcaklığ $100^{\circ} \mathrm{C}^{\prime}$ dir ve klima santrali girişi için eşitlik 22. ile hesaplanır.

$$
X_{K S 2}=\dot{m}_{K S}\left[\left(h_{K S 2}-h_{0}\right)-T_{0}\left(s_{K S 2}-s_{0}\right)\right]
$$

Klima santrali hattında oluşan toplam ekserjik kayıp,

Klima santrali hattındaki ekserjik değişkenler belirlendikten sonra eşitlik hesaplanır.

$$
\begin{gathered}
\Sigma X_{\text {giren }}=\Sigma X_{c ̧ l k a n}+\Sigma X_{\text {kayıp }} \\
X_{K S 1}=X_{K S 2}+X_{\text {Kayıp }} \\
X_{\text {Kayıp }}=X_{K S 1}-X_{K S 2}
\end{gathered}
$$

\subsection{Fan Coil Hattının Ekserji Analizi}

Aşağıdaki şematik gösterimde fan coil hattının ekserjik değişkenleri gösterilmiştir.

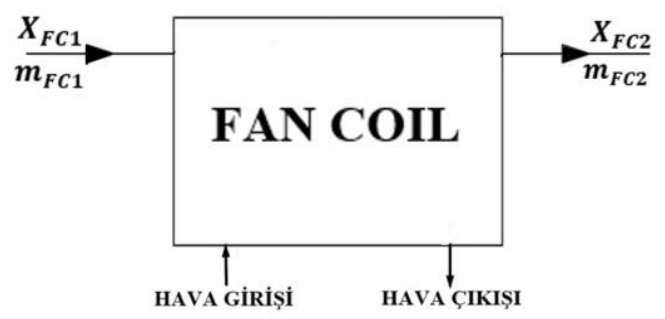

Şekil 9. Fan coil hattının ekserjik değişkenleri

Fan coil hattının girişinde ekserji değeri hesaplanırken fan coil hattına girişteki su sıcaklığ $70{ }^{\circ} \mathrm{C}$ ' olduğundan suyun bu sıcaklıktaki termodinamiksel özellikleri ve aşağıdaki eşitlik yardımıyla bulunur.

$$
X_{F C 1}=\dot{m}_{F C}\left[\left(h_{F C 1}-h_{0}\right)-T_{0}\left(s_{F C 1}-s_{0}\right)\right]
$$

Fan coil hatıının çıkışında ekserji değeri için su fan coil hattından $60^{\circ} \mathrm{C}$ 'de çıkmaktadır. Çıkış ekserji değeri aşağıdaki eşitlik yardımıyla hesaplanır.

$$
X_{F C 2}=\dot{m}_{F C}\left[\left(h_{F C 2}-h_{0}\right)-T_{0}\left(s_{F C 2}-s_{0}\right)\right]
$$

Fan coil hattının toplam ekserjik kaybı, fan coil hattı için gerekli değişkenler hesaplandıktan sonra aşağıdaki eşitlikler yardımıyla toplam ekserjik kayıp Eşitlik 30. ile hesaplanır.

$$
\begin{gathered}
\Sigma X_{\text {giren }}=\Sigma X_{\text {çlkan }}+\Sigma X_{\text {kayıp }} \\
X_{F C 1}=X_{F C 2}+X_{\text {Kayıp }} \\
X_{\text {Kayıp }}=X_{F C 1}-X_{F C 2}
\end{gathered}
$$

\subsection{Eşanjör Sisteminin Ekserji Analizi}

Eşanjör hattı mühendislik fakültesi D ve E blokta sıcak su üretimi amacıyla kullanılmaktadır. Bu hat ile sıcak su devresinden elde edilen isı kazancı, soğuk suya aktarılmakta ve böylelikle kullanım sıcak su ihtiyacı karşılanmaktadır. Şehir şebekesinden $5{ }^{\circ} \mathrm{C}$ ' de gelen kullanım sıcak suyu $40{ }^{\circ} \mathrm{C}$ 'de kullanım alanlarına iletilmekte ve kazandan $90{ }^{\circ} \mathrm{C}$ 'de çıkan eşanjör ssıtma suyu ise, $70{ }^{\circ} \mathrm{C}$ 'de kazana geri dönmektedir. 


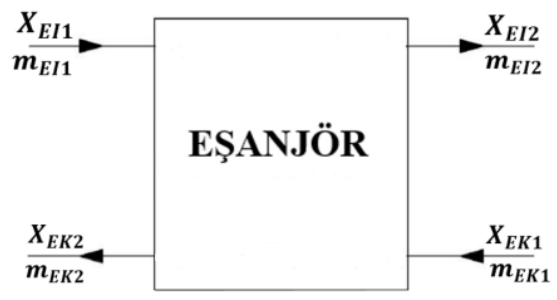

Şekil 10. Eşanjör sistemi ekserjik değişkenleri

Eşanjör hattı 1sıtma devresinin girişindeki ekserjik değer,

Eşanjör hattı 1sıtma devresinin girişindeki su sıcaklığg $187,5^{\circ} \mathrm{C}$ 'dir ve giriş ekserji değeri aşağıdaki eşitlik yardımıyla hesaplanır.

$$
X_{E I 1}=\dot{m}_{E I}\left[\left(h_{E 1}-h_{0}\right)-T_{0}\left(s_{E 1}-s_{0}\right)\right]
$$

Eşanjör hattı ısıtma devresinin çıkışındaki ekserjik değer ise

Eşanjör hattı 1sıtma devresinin çıkışındaki su sıcaklığı $60{ }^{\circ} \mathrm{C}$ 'dir ve çıkış ekserji değeri aşağıdaki eşitlik yardimiyla hesaplanır.

$$
X_{E I 2}=\dot{m}_{E I}\left[\left(h_{E 2}-h_{0}\right)-T_{0}\left(s_{E 2}-s_{0}\right)\right]
$$

Eşanjör hattı kullanım suyu devresinin girişindeki ekserjik değer,

Eşanjör hattı kullanım suyu devresinin girişindeki su sıcaklığ $15^{\circ} \mathrm{C}$ 'dir ve giriş ekserji değeri aşağıdaki eşitlikle hesaplanır.

$$
X_{E K 1}=\dot{m}_{E K}\left[\left(h_{E 3}-h_{0}\right)-T_{0}\left(s_{E 3}-s_{0}\right)\right]
$$

Eşnajör hattı kullanım suyu devresinin çıkışındaki ekserjik değeri,

Eşanjör hattı kullanım suyu devresinin çıkışındaki su sıcaklığı $50{ }^{\circ} \mathrm{C}$ ' dir ve çıkış ekserji değeri aşağıdaki eşitlik yardımıyla hesaplanır.

$$
X_{E K 2}=\dot{m}_{E K}\left[\left(h_{E 4}-h_{0}\right)-T_{0}\left(s_{E 4}-s_{0}\right)\right]
$$

Eşanjör hattının toplam ekserjik kaybı, Eşitlik 37. yardımıyla hesaplanır.

$$
\begin{gathered}
\Sigma X_{\text {giren }}=\Sigma X_{\text {çlkan }}+\Sigma X_{\text {kayıp }} \\
X_{E I 1}+X_{E K 1}=X_{E I 2}+X_{E K 2}+X_{\text {Kayıp }} \\
X_{\text {Kayıp }}=X_{E I 1}+X_{E K 1}-\left(X_{E I 2}+X_{E K 2}\right)
\end{gathered}
$$

Sistem üzerindeki tüm elemanların ekserji değerleri hesaplandıktan sonra ekserjik verim değeri Eş.38 ile hesaplanır.

$$
\eta_{\Pi}=\frac{\sum X_{c ̧ l k a n}}{\sum X_{\text {giren }}}
$$

\section{Sonuç}

Isı santralinde 1sıtma tesisatlarının enerji analizleri yapıldıktan sonra detaylı sonuçlar elde edebilmek ve kayıp noktalarını belirleyebilmek için sistemin her elemanına ayrı ayrı ekserji analizleri yapılmıştır. Yapılan analizler ve hesaplanan sonuçlar tablolarda belirtilmiştir. Hesaplanan enerji, entropi ve ekserji değerleri Tablo 1.1 ' de gösterilmiştir. 
Çizelge 1.1 Isıtma sistemi elemanlarının özellikleri ve noktasal ekserji miktarları

\begin{tabular}{|c|c|c|c|c|c|c|c|}
\hline No & Açıklama & $\begin{array}{c}\text { Akışkan } \\
\text { Tipi }\end{array}$ & $\begin{array}{c}\text { Sicakliğ } 1 \\
T\left({ }^{\circ} C\right)\end{array}$ & $\begin{array}{c}\text { Entalpi } \\
h \\
(k J / k g)\end{array}$ & $\begin{array}{c}\text { Entropi } \\
s \\
(k J / k g K)\end{array}$ & $\begin{array}{c}\text { Kütlesel } \\
\text { Debi } \\
\dot{m}(\mathrm{~kg} / \mathrm{s})\end{array}$ & $\begin{array}{c}\text { Ekserji } \\
\text { Miktarı } \\
(k W)\end{array}$ \\
\hline 1 & Kazan girişi & $\mathrm{Su}$ & 70 & 293.07 & 0.9551 & 80 & 1295.6 \\
\hline 2 & Kazan çıkışı & $\mathrm{Su}$ & 90 & 377.04 & 1.1929 & 80 & 2438.8 \\
\hline 3 & Klima santrali giriş & $\mathrm{Su}$ & 90 & 377.04 & 1.1929 & 63.75 & 1942.44 \\
\hline 4 & Klima santrali çıkış & $\mathrm{Su}$ & 70 & 293.07 & 0.9551 & 63.75 & 1031.16 \\
\hline 5 & Fan coil girişi & $\mathrm{Su}$ & 70 & 293.07 & 0.9551 & 4.44 & 71.86 \\
\hline 6 & Fan coil çıkışı & $\mathrm{Su}$ & 60 & 251.17 & 0.8313 & 4.44 & 46.88 \\
\hline 7 & Eşanjör 1sıtma girişi & $\mathrm{Su}$ & 87,5 & 366.5 & 1.1637 & 11.81 & 336.41 \\
\hline 8 & Eşanjör 1sitma çıkış1 & $\mathrm{Su}$ & 60 & 251.18 & 0.8313 & 11.81 & 124.69 \\
\hline 9 & Eşanjör girişi & $\mathrm{Su}$ & 5 & 21.02 & 0.0763 & 11.81 & 19.05 \\
\hline 10 & Eşanjör çıkışı & $\mathrm{Su}$ & 50 & 209.34 & 0.7038 & 11.81 & 71.75 \\
\hline
\end{tabular}

Tablo 1.1' de verilen ekserji miktarları kullanılarak hesaplanan ekserji kayıp değerleri gösterilmiştir. Ekserjik verim değerleri Tablo 1.2 'de gösterilmiştir.

Çizelge 1.2 Isıtma sistemindeki elemanların ekserjik kayıp ve verim değerleri

\begin{tabular}{|c|c|c|c|c|c|}
\hline $\begin{array}{c}\text { Cihaz } \\
\text { No }\end{array}$ & Cihaz İsmi & $\begin{array}{c}\Sigma X_{\text {giren }} \\
(k W)\end{array}$ & $\begin{array}{c}\Sigma X_{\text {çlkan }} \\
(k W)\end{array}$ & $\begin{array}{c}\Sigma X_{\text {Kayıp }} \\
(k W)\end{array}$ & $\begin{array}{c}\text { Ekserjik } \\
\text { Verim } \\
(\Pi)\end{array}$ \\
\hline 1 & Kazan & 8791.1 & 2723.37 & 6067.73 & 0.3097 \\
\hline 2 & Klima Santrali & 1942.44 & 1031.16 & 911.28 & 0.5308 \\
\hline 3 & Fan Coil & 71.86 & 46.88 & 24.98 & 0.6523 \\
\hline 4 & Eşanjör & 355.46 & 196.44 & 159.02 & 0.5526 \\
\hline
\end{tabular}

Elde edilen verim ve ekserjik kayıp verilerini değerlendirmek için aşağıdaki Grassman diyagramı çizilmiştir.

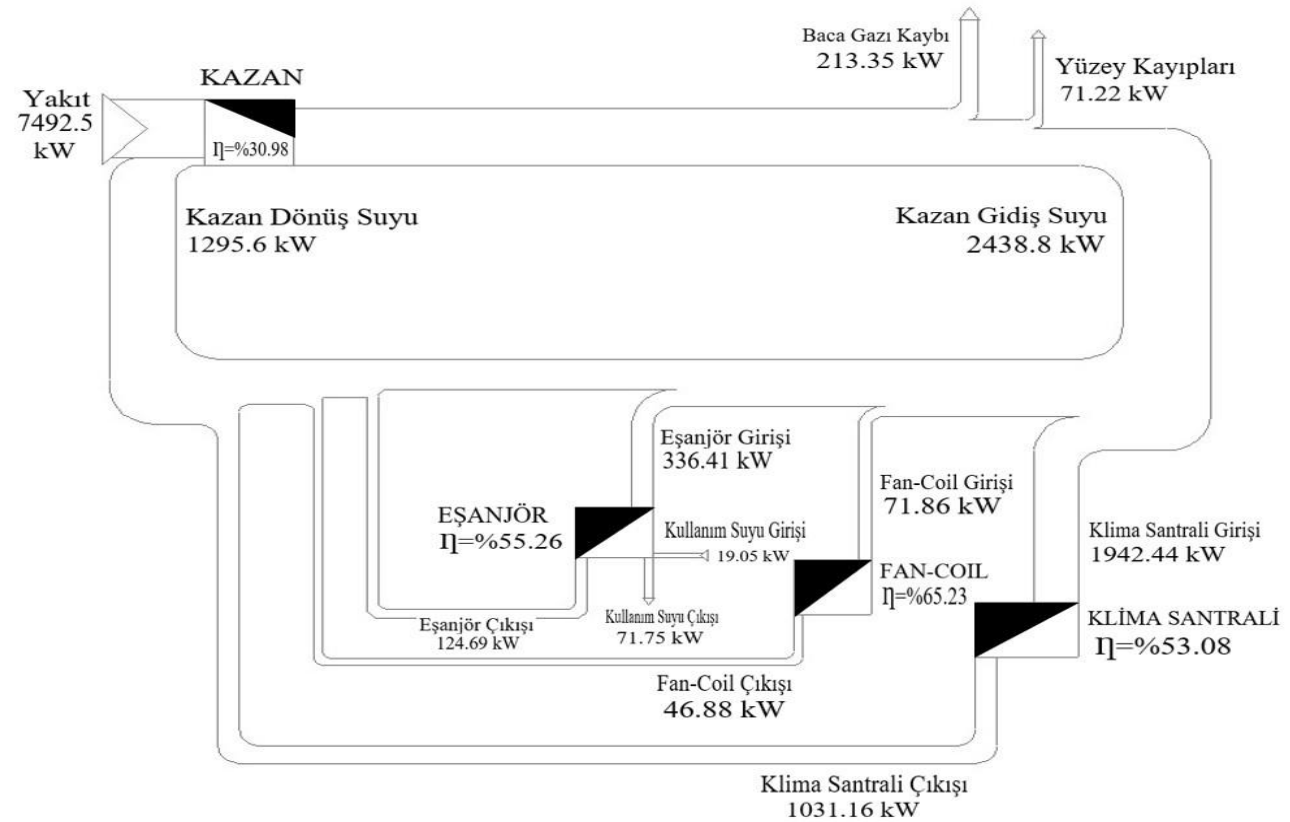

Şekil 11. KSÜ ısı santrali Grassman diyagramı 
Hesap sonuçlarına göre Grassman diyagramı tüm cihazlar için ayrı ayrı kullanılabilir enerji ve tersinmezlikleri göstermektedir. Ayrıca bu diyağram kayıpların fazla olduğu yerleri belirleyerek verim artırıcı çözümlerin uygulanmasını kolaylaştırmaktadır. Sonuçlar değerlendirildiğinde ekserji kaybının en fazla kazanda olduğu görülmektedir. Isıtma sistemlerinde ekserji verimi yüksek olan, düşük ekserji kaybı olan, ısıtma ve soğutma donanımları kullanılmalıdır.

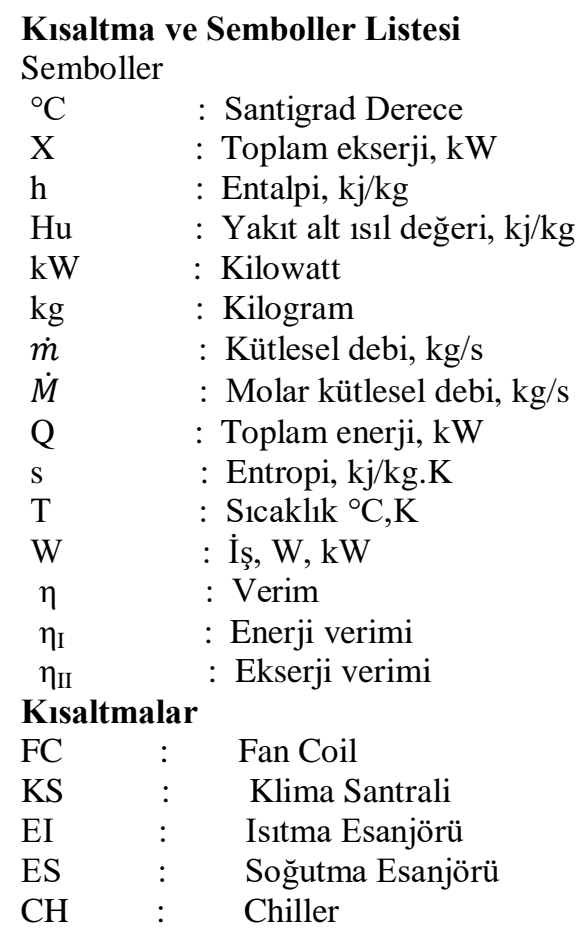

\section{Kaynaklar}

Aljundi Isam H. 2009, Energy and exergy analysis of a steam power plant in Jordan. Chemical Engineering Department, Mutah University, Al-Karak, Jordan; 29: 324-28.

Bilgen, S. 2000. "Bazı Yakıtların Kimyasal Ekserji Değerlerinin Hesaplanması,” Yüksek Lisans Tezi, Karadeniz Teknik Üniversitesi, Fen Bilimleri Enstitüsü, Trabzon.

Çomaklı, K. 2003. "Atatürk Üniversitesi Isıtma Merkezinin Enerji ve Ekserji Analizi,” Doktora Tezi, Atatürk Üniversitesi, Fen Bilimleri Enstitüsü, Erzurum.

Coşkun, A., Geredelioğlu, Ç., Bolattürk, A., Gökaslan, M. Y. 2013. "Çayırhan Termik Santralinin Enerji ve Ekserji Analizi,” 11. Ulusal Tesisat Mühendisliği Kongresi, 17-20/04/2013, İzmir.

Dragan M, Uzuneanu K, Panait T, Gelu C. 2011. The exergetic evaluation for the steam boiler, Thermal Engineering and Environment (HTE'11), Florence, Italy.

Doldersum A. 1998, Exergy analysis proves viability of process modifications. Energy Conversion and Management ; 39 (16-18): 1781-89.

Filiz, Ç., Uysal, C., Kılı̧̧, E., Kurt, H. 2014. "Bir Buhar Kazanının Enerji ve Ekserji Analizi Yoluyla Performansının Değerlendirilmesi," 2nd International Symposium on Innovative Techonologies in Engineering and Science, 26-27/06/2014, Karabük. 
Güngör A, Karaçaylı İ, Şimşek E ve Canlı Y., 2017. "Geri Dönüş Havalı İklimlendirme Sistemlerinde Enerji ve Ekserji Analizi," Çukurova Üniversitesi Mühendislik Mimarlık Fakültesi Dergisi, 32(3): 19-29.

Habib MA, Said SAM, Al Zaharana I. 1999, Thermodynamic optimization of reheat regenerative thermal-power plants. Applied Energy; 63: 17-34.

Kopaç M, Zemher B.2004, Exergy analysis of the steam-injected gas turbine. Int. Journal of Exergy; 1 (3): 363-74.

Kaushik, S. C., Singh, O. K. 2014. "Estimation of Chemical Exergy of Solid, Liquid and Gaseous Fuels Used in Thermal Power Plants," J Therm Anal Calorim, vol. 115, p. 903- 908.

Mançuhan, E. 2011. "Yaş Tuğla Kurutulan Bir Tünel Kurutucuda Enerji ve Ekserji Analizi, Tesisat Mühendisliği Dergisi, sayı 120, s. 35-42.

Saidur, R., Ahamed, J. U., Masjuki H. H. 2010. "Energy, Exergy and Economic Analysis of Industrial Boilers," Energy Policy, vol. 38, p. 2188-2197.

Sinanoğlu, U., Esen, D. Ö., Karakaş, E. 1996. "Enerji Ekonomisi Açısından Geri Kazanım Sistemleri," TMMOB 1. Enerji Sempozyumu, 12-14/11/1996, Ankara.

Szargut, J. 2005. Exergy Method, Technical and Ecological Applications, WIT Press, Southampton, UK.

Pak PS., Suzuki Y., 1997, Exergetic evaluation of gas turbine cogeneration systems for district heating and cooling. International Journal of Energy Research , 21: 209-20.

Tsatsaronis G., 1993. Thermoeconomic analysis and optimization of energy systems. Progress in Energy and Combustion Science, 19 (3): 227-57.

Willems, D. 2006. "Advanced System Controls and Energy Savings for Industrial Boilers," Transactions of the Citrus Engineering Conference, Florida, vol. 52, p.11-22. 